\title{
THE SUPPORT SYSTEM OF THE VICTIM EVACUATION PROCESS IN MASS-CASUALTY INCIDENTS
}

\author{
Mirosław DEREN ${ }^{1}$, Ryszard GROSSET ${ }^{2}$, Paweł POMASKI ${ }^{1}$, Marcin PIOTROWSKI ${ }^{1}$, Łukasz \\ DZIUDA $^{1}$ \\ ${ }^{1}$ Military Institute of Aviation Medicine, Warsaw, Poland \\ ${ }^{2}$ Main School of Fire Service, Warsaw, Poland
}

Source of support: The system of evacuation and rescue of victims of natural disasters was developed within the framework of the EvaCopNet project, co-financed by the National Centre for Research and Development (NCRD) (Contract No. PBS3/B9/37/2015).

Author's address: M. Dereń, Military Institute of Aviation Medicine, Krasińskiego 54/56 Street, 01755 Warsaw, Poland, e-mail: mderen@wiml.waw.pl

Abstract: In the case of mass events in which the number of victims exceeds the rescue capability of qualified medical assistance units, emergency medical evacuation systems are created and developed for all the victims of an incident. The presented system is designed to support the process of evacuation and rescue of victims. It covers the following areas of technical solutions: the FT (FlagTag) victim tagging micro-module, the radio module and MESH network organization using unmanned aerial vehicles, the Q-Find victim location module, as well as the data integrator software module. The authors described the functions and direction of development for the FT victim tagging micro-module.

The practical aim of the project was to develop technical solutions for contactless measurement of basic vital functions and spatial marking of victims of natural disasters, with the help of sensory elements and wireless data transmission using the MESH technology that also relies on unmanned aerial vehicles (UAVs).

It is the only such technological solution in Poland, on the basis of which it is possible to develop a fully functional system of evacuation and rescue with elements of monitoring of victims of major catastrophes or natural disasters.

Keywords: biomedical electronics, blood saturation, rescue, MESH networks, biological parameters sensors, pulse

Figures: 9 - Table: 1 - References: 11 - Full-text PDF: http://www.pjambp.com • Copyright (C) 2017 Polish Aviation Medicine Society, ul. Krasińskiego 54/56, 01-755 Warsaw, license WIML • Indexation: Index Copernicus, Polish Ministry of Science and Higher Education 


\section{INTRODUCTION}

During a year, there may be a dozen or so events in which the rescue capability of qualified medical aid units (State Emergency Medical Services) is insufficient for completely meeting the needs of medical evacuation in an emergency that is lifethreatening to all the victims of the event. Prospects for the development of transport technologies (development of the network of motorways and expressways, high-speed railways, development of air transport) point to an inevitable increase in the number of cases of mass character, in which the problem of additional tools supporting victim segregation ("triage") [2] is a critical element. Also the annually recurring natural disasters (floods, hurricanes, fires, snowstorms) indicate the need to develop systems allowing to optimize rescue operations for people in conditions of dispersion.

Since 1995, the National Rescue and Firefighting System has been operated by the State Fire Service. The aim of the system was to create a unified arrangement bringing together various interlinked rescue entities, thanks to which it would be possible to effectively undertake all rescue activities aimed primarily at saving life and health.

On the basis of concluded agreements, the system is supported by services, inspection bodies and guards, among others: the Police, Border Guard, National Environmental Protection Inspection Authority, Institute of Meteorology and Water Management, National Atomic Energy Agency, Mining Rescue Stations, Maritime Search and Rescue Service (SAR), Air Rescue Service, as well as non-governmental organizations: GOPR, WOPR, TOPR, Aeroklub Polski, ZHP, PCK, Polski Związek Alpinizmu. The principles of implementation of basic rescue operations are supposed to be constant also in the case of mass events and natural disasters. But the organization and scope of the operations themselves requires modification and optimization of procedures in order to minimize the time needed to effectively carry out the operations and to introduce new technical solutions improving the operational efficiency of rescue units and teams, especially in the case of mass events, in which the number of injured persons is significant [8]. Simplifications of procedures are a result of the commonly occurring threats to life and health of rescuers during mass events. Under these conditions, rescuers who give first aid and who classify victims as a particular group and, at the same time, the operations of teams which evacuate the victims, should be perfectly coordinated. Among the systems of victim segregation used in Poland, referred to in the international nomenclature as "triage" [6], the most commonly used is the START system (Simple Triage and Rapid Treatment), which, in a simplified form, is used by rescuers who do not have adequate medical education. As a result, in the assumptions of the technical solution being developed, the victims will, as part of primary (initial) segregation and after all the necessary rescue actions have been taken, be tagged with three colors determining the life threatening state and at the same time the priority of providing further medical assistance:

- green - the victim can walk - he/she will survive, regardless of the type of help provided,

- yellow - the victim cannot walk, he/she follows simple instructions - the injuries do not directly endanger life,

- red - a victim whose life is directly endangered - evacuation to a medical point should take place as soon as possible.

The appropriately colored tags that have been used until now, affixed to the injured person, will be replaced with the electronic FT victim tagging micro-module. According to the assumptions, the FT victim tagging micro-module has been developed in the form of a band placed on the injured person's limb (FT band).

\section{STRUCTURE OF THE SYSTEM}

The structure of the system supporting the process of evacuation and rescue of victims of natural disasters (Fig. 1) consists of the following:

- radio modules for organization and communication in the MESH network that are placed throughout the area of the event. The radio modules (built into FT bands, UAVs, Q-Find modules and other equipment) will automatically and autonomously form a communication network. The radio modules will be able to act as transmitting, receiving and intermediary nodes. The network will find the optimal connections for the sent messages by dynamically selecting the nodes that mediate the transmission. The use of UAVs makes it possible to organize MESH networks in hard-to-reach terrain,

- FT bands equipped with radio modules enable the victim to be tagged with the correct color after segregation. At the same time, they enable the victim to be located in a geographical coordinate system (GPS) and enable monitoring of certain vital parameters of the victim [2],

- Q-Find modules are equipped with radio modules used to locate the victims, 


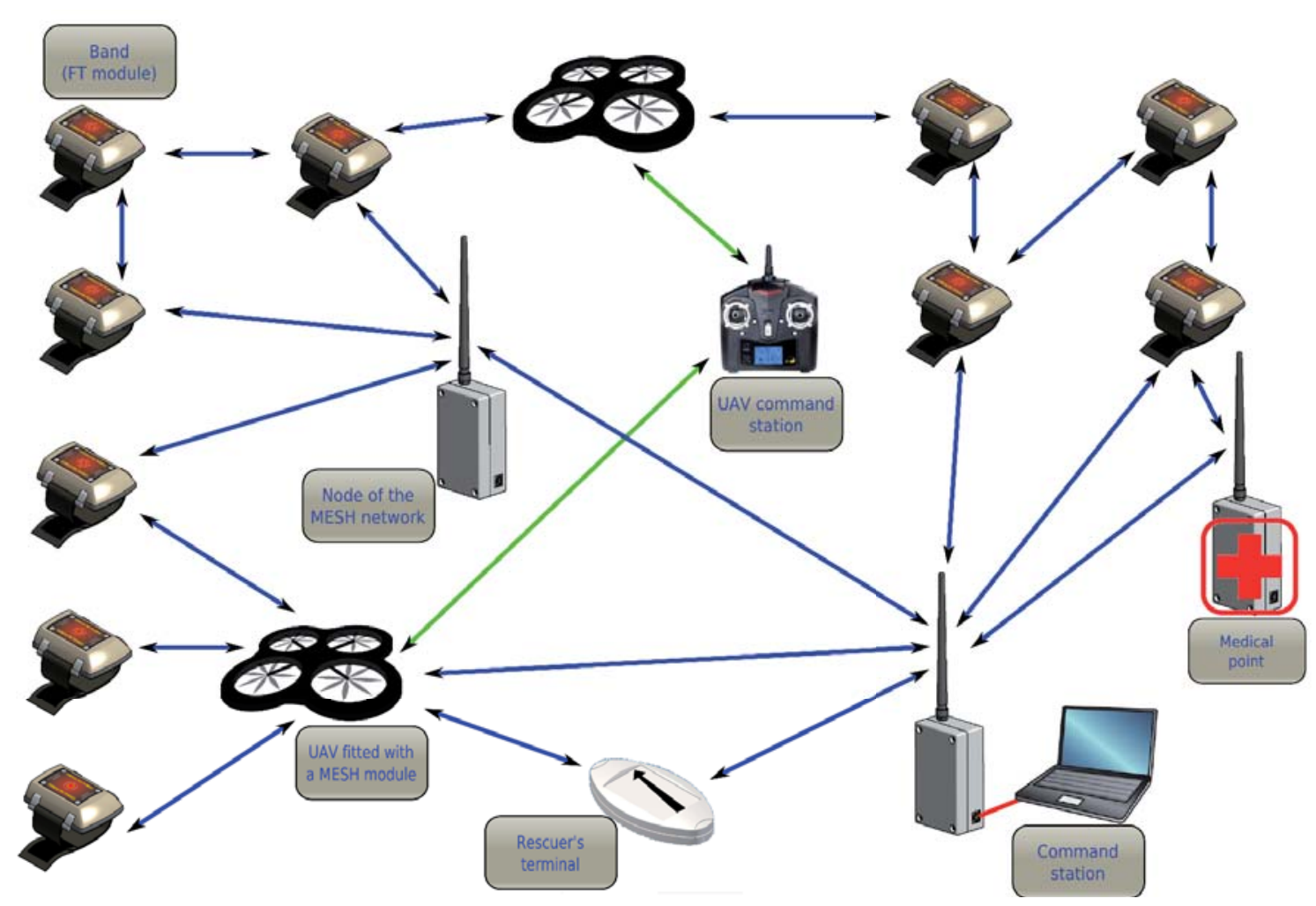

Fig. 1. Diagram of the EvaCopNet system.

- modules of the data integrator (coordinator) which is equipped with radio modules and which enables collection of data from the system, their analysis and management of the system. The task of the coordinator module is to assist the leader of the rescue operation.

\section{STAGES OF STRUCTURAL DEVELOPMENT OF THE EVACOPNET SYSTEM'S FT BAND}

As a result of the analyses carried out, preliminary functional and technical assumptions were made for the FT band. On this basis, a model solution (Fig. 2) was developed which enabled the integration of such components as: the MESH

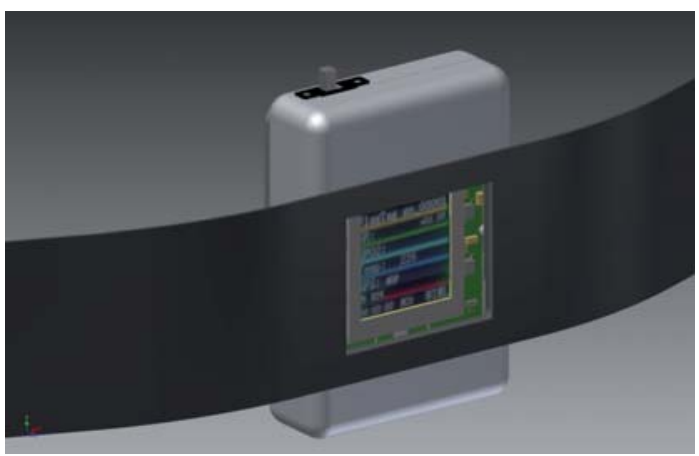

a) network's radio module, battery, wireless power supply, OLED RGB display, triage status LED set, GPS location module, motherboard and sensors: pulse-oximetric $\left(\mathrm{SpO}_{2}\right)[4,9]$, contactless body temperature sensor and ambient temperature sensor, acceleration sensor.

The OLED RGB 96 × 6416 bit display used in the model of the FT band (Fig. 2) enabled direct monitoring of the status of the band and its functions (Fig. 3).

The SpO2 sensor used in the FT band, by means of two LEDs emitting light waves of different lengths, illuminates blood vessels in limb tissues and simultaneously measures the amount of returning light [10]. Using Lambert Beer's law, the percentage of hemoglobin with oxygen in the

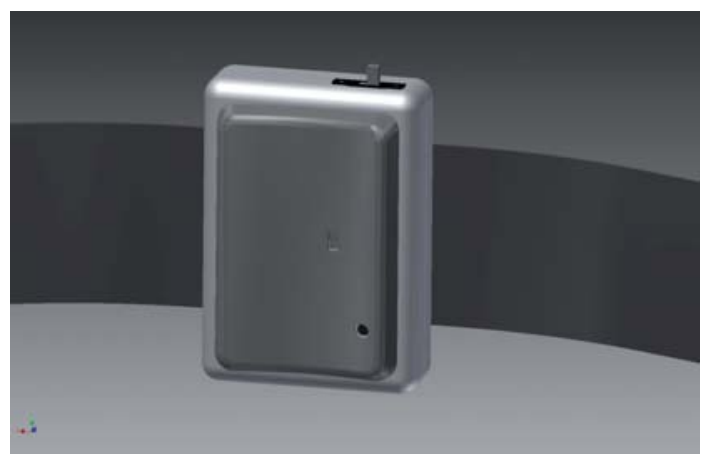

b)

Fig. 2. Visualization of the FT band's design: a) display side, b) sensor side. 


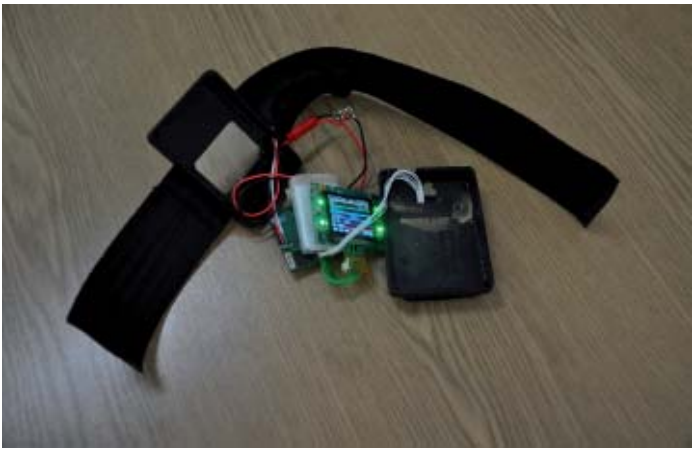

a)

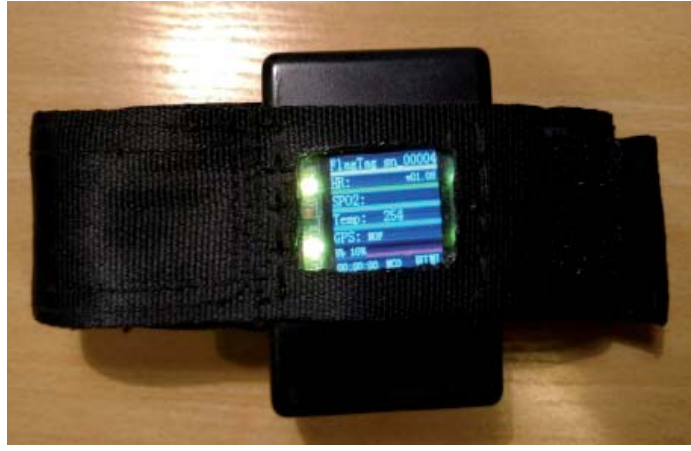

b)

Fig. 3. Model of the FT band: a) real model (open housing), b) displayed parameters of the band.

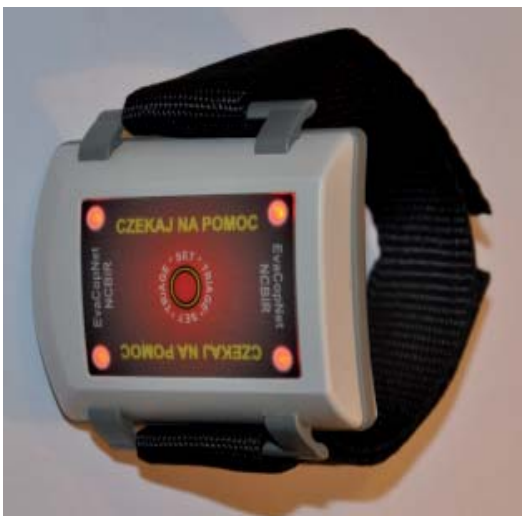

a)

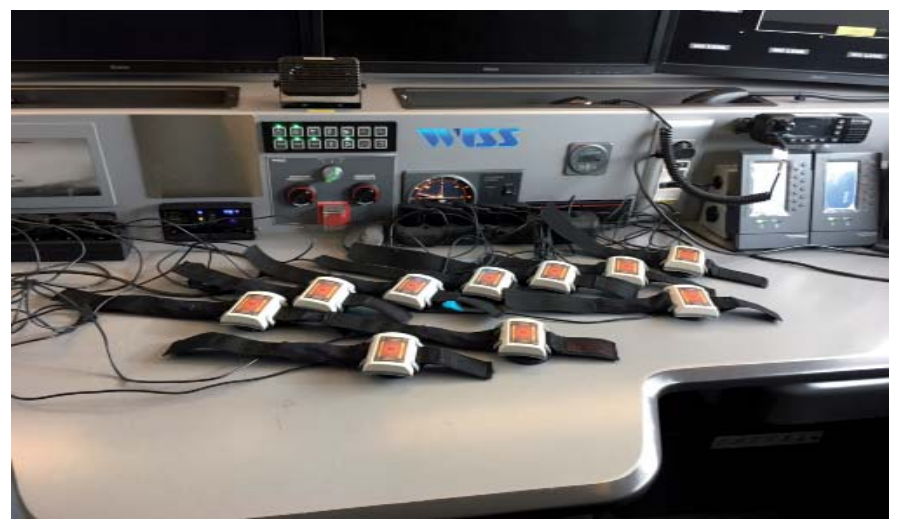

b)

Fig. 4. Prototype FT band: a) one piece, b) charging of the bands at the command station.

blood $\left(\mathrm{SpO}_{2}\right)$ is calculated based on the spectrum absorption characteristics of reduced hemoglobin and oxyhemoglobin. At the same time, it is possible to determine the pulse wave and, on this basis, to calculate the heart rate $(\mathrm{HR})[3,4,11]$. Both parameters are used to assess the health status.

At the initial stage, the DCM05 sensor was planned to be used. However, the MAX30100 sensor was used to build the model. It is characterized by a completely digital communication interface, a very low power consumption (approx. $0.7 \mu \mathrm{A}$ ) and it does not require any calibration, as opposed to the former.

As a result of further works on the system for evacuation and rescue of victims of natural disasters, certain functional assumptions for the FT band were changed.

1. The display was abandoned. During the rescue operation, the rescuer will not control the parameters measured by the band. This will be due to lack of time and, probably, environmental conditions.

2. The procedure for activating the FT band and determining the victim's status was simplified. A large, easily accessible button was installed in place of the display, to activate the band and then to set the desired color. The band is activated by pressing the button once. Subse- quent presses of the button change the color of the signaling LEDs, in the following order: from green to yellow, from yellow to red, from red to green, etc. The signaling LEDs shine in an intermittent way. Not pressing the button for 10 seconds causes its function to be locked and the signaling LEDs to shine continuously, maintaining the last set color. The band then communicates with the coordinator by transmitting, among other things, its status in which it sends its current color according to the radio data exchange protocol.

Functional assumptions and technical requirements were verified for the existing solution and, on this basis, a prototype batch of FT bands was made (Fig. 4).

The solution was developed, with the following functions.

1. It has an implemented MESH network radio module.

2. It allows to measure one's own position using GPS.

3. It allows to measure two temperatures: in the space between the FT module and the limb in the range of $20-45^{\circ} \mathrm{C}$, and the ambient temperature in the range of $-15^{\circ} \mathrm{C}+60^{\circ} \mathrm{C}$. 
4. It enables identification of the victim's condition (triage) by means of four tri-color LEDs (information about the victim's condition can also be provided by the coordinator via the MESH network).

5. It allows to measure the heart rate (HR) after the band has been placed on the limb.

6. It enables measurement of $\mathrm{SpO}_{2}$ after the band has been placed on the limb.

7. It allows to measure the values of linear acceleration, angular acceleration and the direction of gravitational acceleration.

8. Form - casing in the form of a band attached to the limb.

9. Power supply - minimum operating time of 4 hours using the built-in battery.

10.It has an external wireless charger utilizing the Qi standard.

11. It enables data transmission: on request, periodically (parameter set remotely by the coordinator).

12.It has an internal micro USB connector (CDC class) enabling diagnostics of the FT band's components.

13.It has a dedicated casing which:

- allows the FT band to be placed and firmly fixed to a human limb (in the vicinity of the wrist or the ankle) as well as measurement of $\mathrm{SpO}_{2}$,

- allows the FT module to be intentionally (not accidentally) activated by means of an easily accessible button, and then enables setting of the LEDs' color - information about the victim's condition,

- has the IPX2 rating.
During the tests on the FT band, it was observed that, depending on the person participating in the study, the measurement of $\mathrm{SpO}_{2}$ and $\mathrm{HR}$ was not in line with the expectations. Therefore, a decision was made to replace the MAX30100EFD+ system with a different measuring system. The MAX30105 system, which uses 3 LEDs (green, red and IR) illuminating the subject of the examination, was selected and tested. The MAX30105 system uses a very sensitive photon detector. During the test of this sensor, it was found that, depending on the place of application of the sensor on the examined person, results are obtained which fall into two groups:

1. Results of measurements taken on a finger. A strong pulse wave signal from the LED illuminating the subject with infrared light, and a weaker (but clear) signal from the LED illuminating the subject with green light (Fig. 5) are obtained.

2. Results of measurements taken on a wrist. A weak or nearly zero pulse wave signal from the LED illuminating the subject with infrared light, and a weak (but acceptable) pulse wave signal from the LED illuminating the subject with green light (Fig. 6) are obtained.

On the basis of the results obtained, a decision was made to replace the previously installed SpO2 sensors in the prototype batch and to use new MAX30105 systems.

The obtained plethysmograms were filtered. Commonly used filters were used: Butterworth filter [1] and DC filter [7]. In addition, a simple

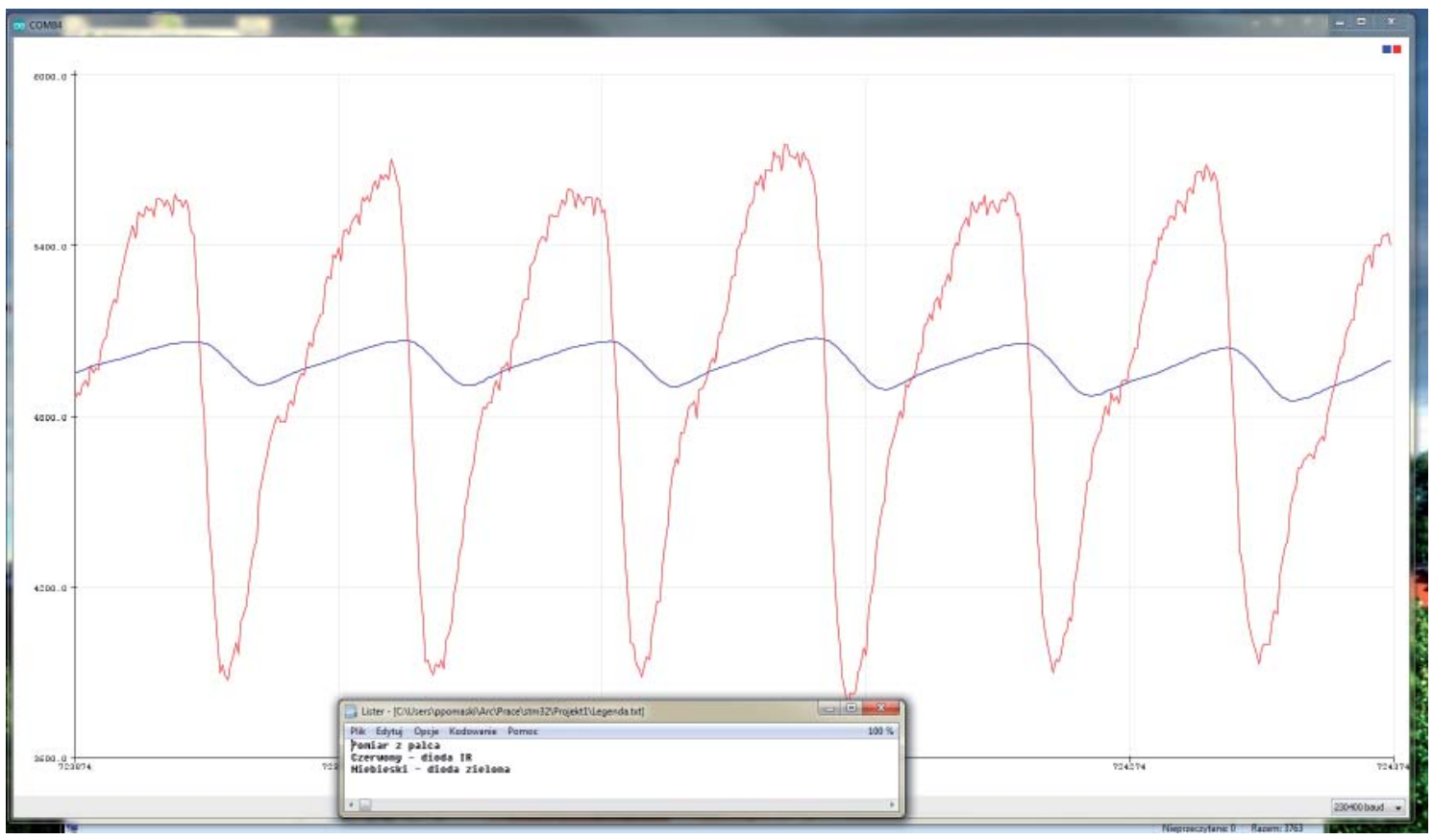

Fig. 5. A pulse wave record. Measurement taken on a finger (scale of the graph was selected automatically). 


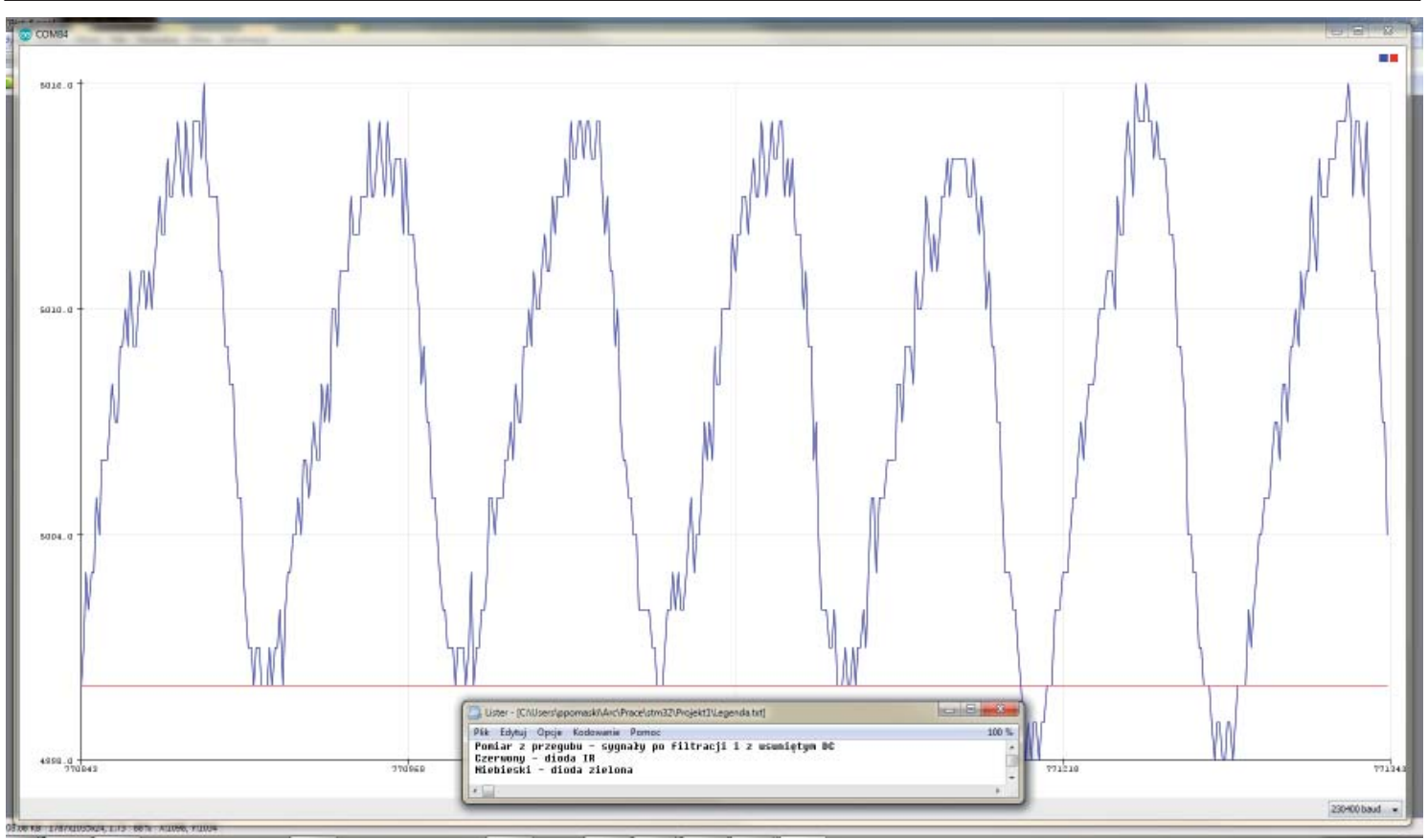

Fig. 6. A pulse wave record. Measurement taken on a wrist (scale of the graph was selected automatically).

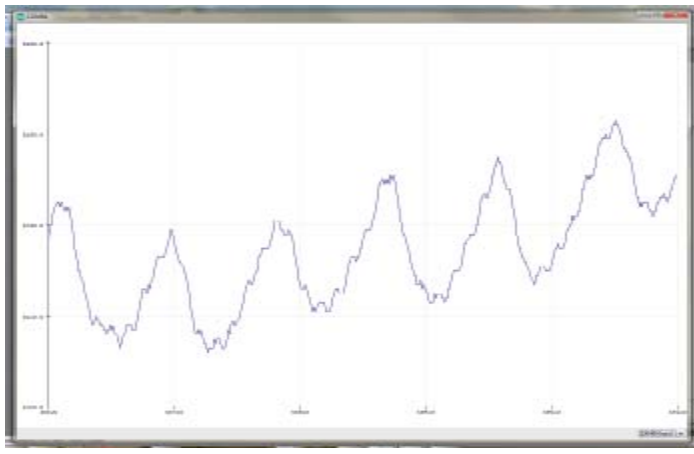

a)

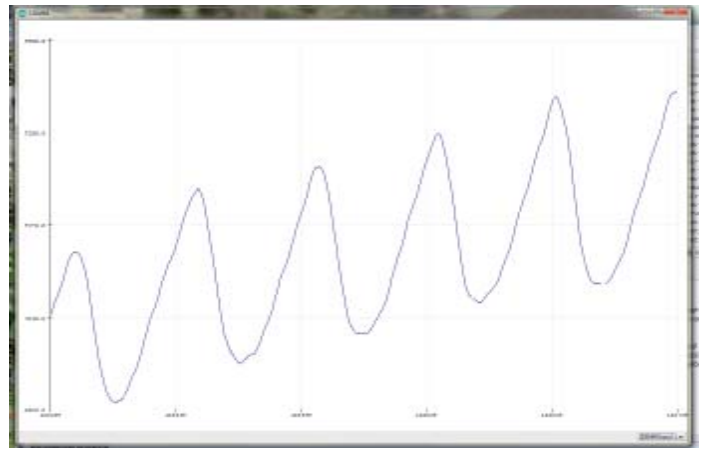

b)

Fig. 7. Examples of plethysmograms after filtration of the signal: a) without filtration; b) commonly used filters and the additional low-pass filter of the 'green channel'.

low-pass filter (Fig. 7) was used at the input of the 'green channel' to facilitate correct determination of extremes, time intervals between them, and then the HR values.

A very important function of the system for evacuation and rescue of victims of natural disasters is the decision-making support provided by the designed system to assess the victim's condition and change the priority of evacuation to a medical point. The system will react to the deterioration of certain parameters measured by the FT band and, if the adopted indicators are exceeded, it will automatically change the color of the FT band on the victim, giving him/her higher evacuation priority. Such a function will be supervised by leader of the rescue operation [5]. A detailed description of the coordinator's actions does not fall within the scope of this paper. But the FT band's function consisting in initial detection of alarm conditions, which, in principle, trigger the executive procedures of the coordinator's system, is important.

The band can send information about the occurrence of an alarm situation ('alarm') to the operator's system at any time, regardless of the predefined time between consecutive reports on the victim's state. According to the adopted data exchange protocol, information on the occurrence of an alarm condition is included in the group of commands called the 'Victim status', which is supplemented with information indicating the cause of the alarm (Tab. 1).

The Alarms field is binary (there can be an alarm condition, or no alarm condition). The following were used: diagrams of information transmission between the components of the system, as well as patterns of decisions made by the software at the 
M. Dereń et al. - The support system...

Tab. 1. Supplementation of the description of the Data exchange protocol's commands (excerpt).

\begin{tabular}{cll}
\hline Size (bytes) & Name & Description \\
\hline 1 & Alarms & $0 \times 1-$ danger - unspecified parameter \\
& $0 \times 2-$ HR - exceeding the critical value \\
& $0 \times 3-$ SpO2 - exceeding the critical value \\
& $0 \times 4-$ tp - exceeding the critical value \\
& $0 \times 5-$ tot - exceeding the critical value \\
\hline
\end{tabular}

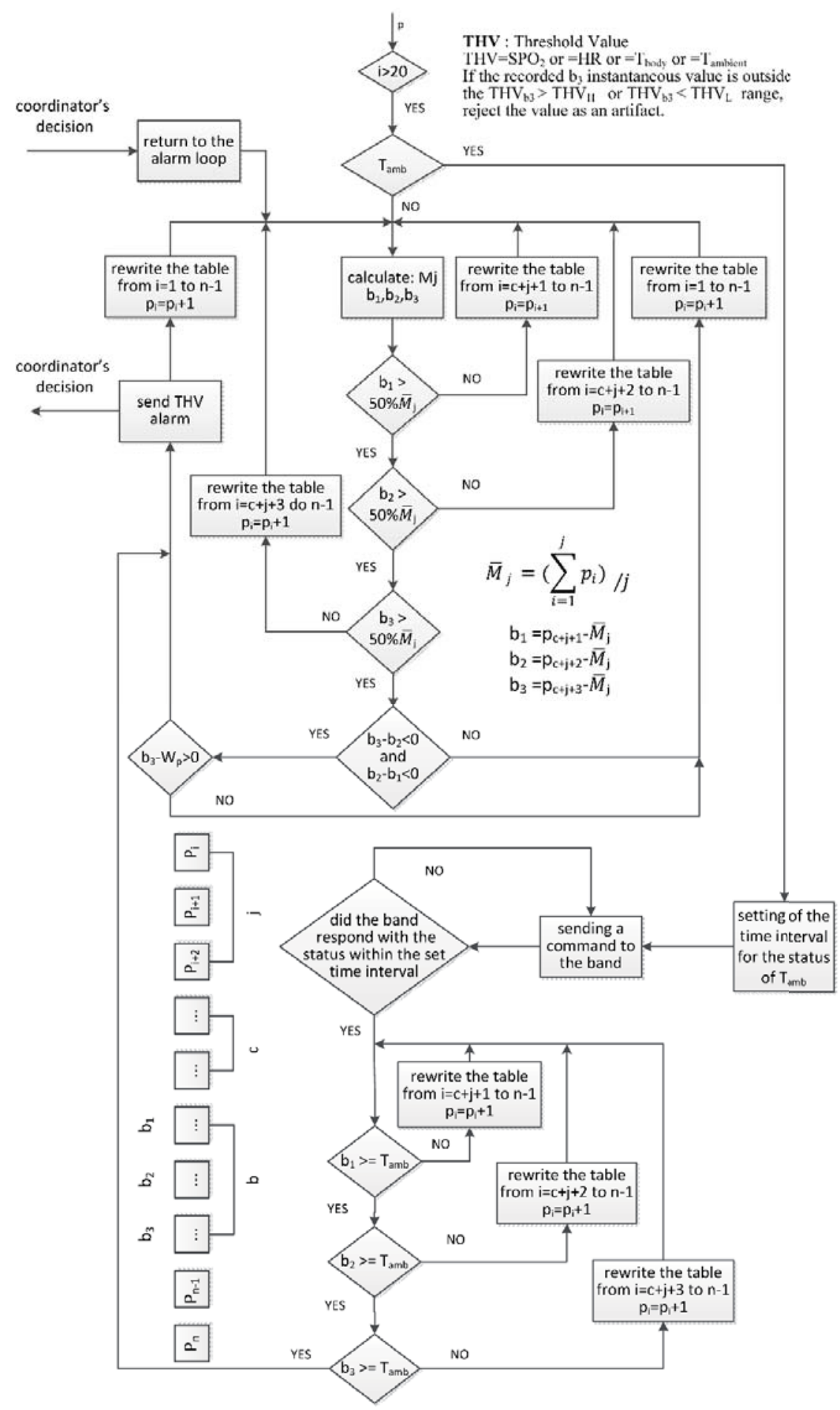

Fig. 8. Diagram of the alarm loop. 


\section{Coordinator's decision}

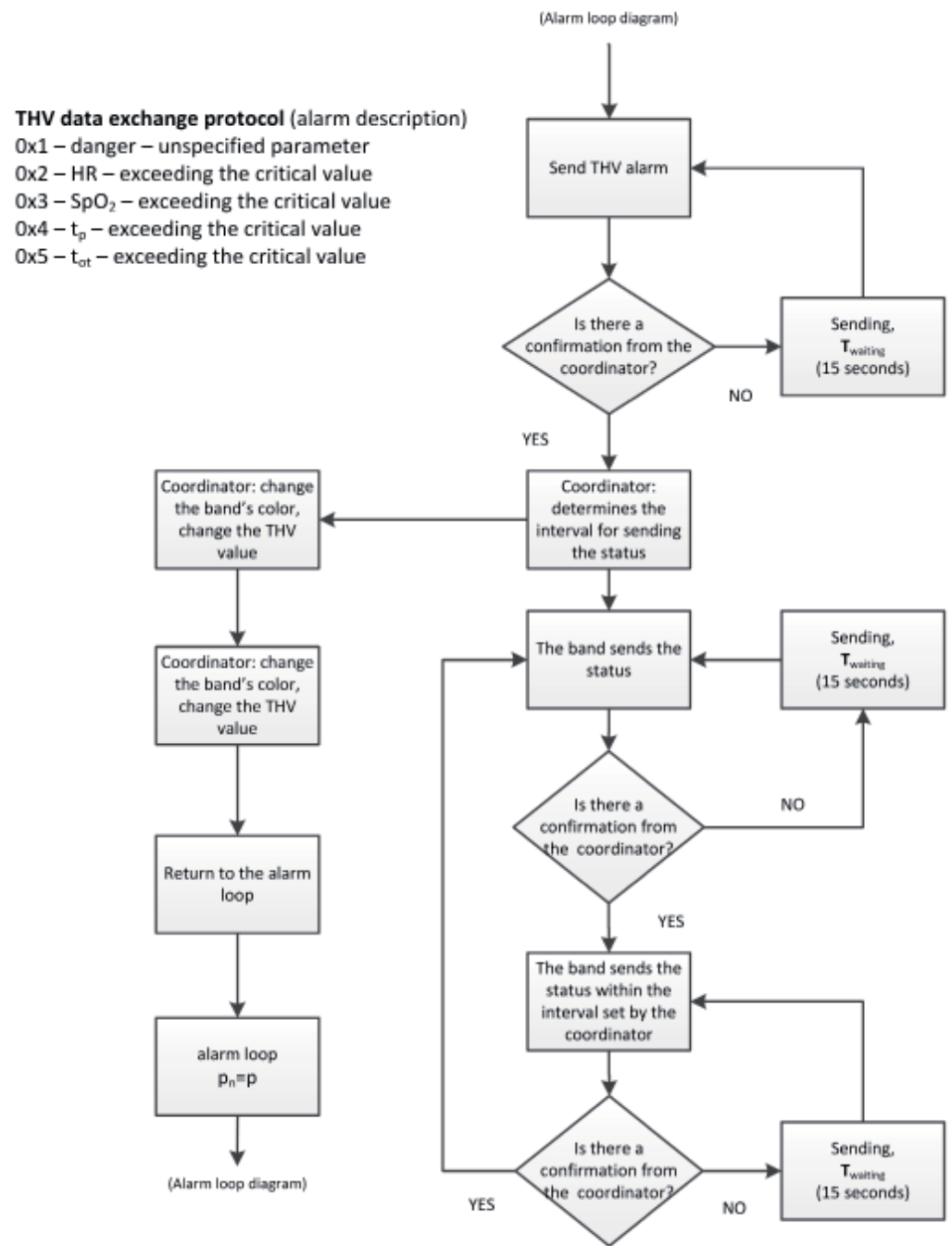

Fig. 9. Executive procedure for decisions made by the coordinator's software.

coordinator's station. Fig. 8 shows a diagram depicting a significant change in sensor parameters measured by means of the $\mathrm{FT}$ band $\left(\mathrm{SpO}_{2}, \mathrm{HR}\right.$, skin temperature / ambient temperature). Fig. 9 shows the decision-making pattern of decisions made by the coordinator's software. A decision of the coordinator's software is made on the basis of a separate algorithm and must be accepted by a human - the rescue operation's leader.

\section{CONCLUSION}

Rescuers, especially of teams operating within the National Rescue and Firefighting System, work in extreme conditions requiring precise organi- zation. The designed systems must therefore be adapted so as to help organize rescue operations. The progress observed in the field of electronics makes it easier to solve some technical problems. However, in order to develop a fully functional evacuation and rescue system, with elements of VICTIM monitoring DURING major catastrophes or natural disasters, it should be successively adapted to the needs of rescuers testing it in the conditions of field exercises. The results of works on the technological solutions of the system achieved so far may be the basis for developing and implementing the target version of the system supporting the evacuation and rescue of victims of natural disasters. 


\section{AUTHORS' DECLARATION:}

Study Design: Mirosław Dereń, Ryszard Grosset, Paweł Pomaski, Marcin Piotrowski, Łukasz Dziuda; Data Collection: Mirosław Dereń, Ryszard Grosset, Paweł Pomaski, Marcin Piotrowski; Manuscript Preparation: Mirosław Dereń, Paweł Pomaski, Marcin Piotrowski, Łukasz Dziuda; Funds Collection: Ryszard Grosset. The Authors declare that there is no conflict of interest.

\section{REFERENCES}

1. Butterworth filter, Retrieved 18 December 2017 from https://en.wikipedia.org/wiki/Butterworth_filter

2. Chan M, et al. Smart wearable systems: Current status and future challenges, Artificial Intelligence in Medicine. 2012; 56:137-156.

3. Czajkowska MA, Rudnicki J, Czajkowski AA, Pietrzak-Sominka J. Mikrokrążenie krwi, tętno i fala tętna, Problemy Nauk Stosowanych. 2014; 2:143-148.

4. Islam MT, et al. A time-frequency domain approach of heart rate estimation from photoplethysmographic (PPG) signal, Biomedical Signal Processing and Control. 2017; 36:146-154.

5. Mills AF, et al. Resource-Based Patient Prioritization in Mass-Casualty Incidents, Manufacturing \& Service Operations Management. 2013; 15:361-377.

6. Raczyński A. Podstawowe założenia systemu segregacji TRIAGE, CRS Triage, Retrived 15.May.2017 from http://www.centrumtriage.pl/system-triage.html

7. Sadik AZ. A Single-Bit Digital DC-Blocker Using Ternary Filtering. 2005; Retrieved 18 December 2017 from https://eprints. qut.edu.au/5914/1/5914_1.pdf

8. Sulikowska L. Nie przenośmy katastrofy do szpitala, "Gazeta Lekarska”. 2017; 1:48-48, 2017; 2:42-43.

9. Sungjoo $\mathrm{H}$, et al. Feasibility analysis of heart rate monitoring of construction workers using a photoplethysmography (PPG) sensor embedded in a wristband-type activity tracker, Automation in Construction. 2016; 71:372-381.

10. Tamura T, Maeda Y, Sekine M, Yoshida M. Wearable Photoplethysmographic Sensors-Past and Present. Electronics. 2014; 3:282-302.

11. Yousefi R, Nourani M, Ostadabbas S, Panahi I. A Motion-Tolerant Adaptive Algorithm for Wearable Photoplethysmographic, Biosensors. IEEE Journal of Biomedical and Health Informatics. 2014; 18(2):670-681.

\section{ACKNOWLEDGEMENTS}

The views, opinions, and findings contained in this article are our own and should not be construed as an official Polish Air Force position, policy, or decision, unless so designated by other official documentation.

Cite this article as: Deren M, Grosset R, Pomaski P, Piotrowski M, Dziuda $Ł$. The Support System of the Victim Evacuation Process in Mass-Casualty Incidents. Pol J Aviat Med Bioeng Psychol 2017; 23(1): 29-37. DOI: 10. 13174/ pj ambp. 19.06. 2018.04 